\title{
Sevoflurane Induction Shortens the Onset of Vecuronium at the Corrugator Supercilii Muscles: A Randomized Comparison with Propofol Induction
}

\author{
Keiichi Nitahara, Yasuyuki Sugi, Go Kusumoto, Kiyoshi Katori, \\ Kohei Iwashita, and Kazuo Higa \\ Department of Anesthesiology, Fukuoka University School of Medicine, Fukuoka 814-0180, Japan \\ Correspondence should be addressed to Keiichi Nitahara, nitahara@fukuoka-u.ac.jp
}

Received 29 September 2011; Accepted 17 October 2011

Academic Editors: S. Baris, J.-H. Baumert, and D. E. Raines

Copyright (C) 2011 Keiichi Nitahara et al. This is an open access article distributed under the Creative Commons Attribution License, which permits unrestricted use, distribution, and reproduction in any medium, provided the original work is properly cited.

\begin{abstract}
We evaluated if induction with sevoflurane shortened the onset of vecuronium-induced neuromuscular blockade at the corrugator supercilii muscles (which have a similar time course of neuromuscular blockade with laryngeal muscles). Thirty-two patients were randomly allocated to a sevoflurane or propofol group. Anesthesia was induced with $5 \%$ sevoflurane in oxygen (sevoflurane group, $n=16$ ) or with propofol $2-2.5 \mathrm{mg} \mathrm{kg}^{-1}$ (propofol group, $\left.n=16\right)$, and vecuronium $\left(0.1 \mathrm{mg} \mathrm{kg}^{-1}\right)$ was given in both groups. Evoked responses to train-of-four stimuli were measured by acceleromyography at the corrugator supercilii and adductor pollicis muscles. Sevoflurane induction, as compared with propofol, significantly shortened the onset time at the corrugator supercilii muscles from $138 \pm 34 \mathrm{~s}$ to $107 \pm 28 \mathrm{~s}(P<0.01)$. Onset time at the corrugator supercilii was significantly shorter than at the adductor pollicis for both groups $(P<0.01)$. Our results suggest that induction with sevoflurane, as compared with propofol, shortened the onset time of vecuronium at laryngeal muscles.
\end{abstract}

\section{Introduction}

Induction and maintenance of anesthesia with sevoflurane has been used in adults owing to its low solubility and nonirritant properties upon the respiratory tract [1-3]. Inhalational anesthetics (including sevoflurane) increase the intensity and duration of nondepolarizing neuromuscularblocking drugs [4-8]. It has been reported that the induction of general anesthesia with sevoflurane shortens the onset time of vecuronium at the adductor pollicis muscles [9]. However, during the induction of general anesthesia, it is important to know the degree of neuromuscular blockade at the laryngeal muscles.

Studies that have evaluated the effects of sevoflurane induction on the onset of nondepolarizing neuromuscularblocking drugs at the laryngeal muscles (or other muscles having similar neuromuscular blocking profiles to the laryngeal muscles) are lacking. It has been reported that the time course of neuromuscular blockade at the corrugator supercilii muscle is similar to that at the laryngeal muscles [10].

We aimed to evaluate if the induction of anesthesia with sevoflurane shortens the onset time of vecuronium $0.1 \mathrm{mg} \mathrm{kg}^{-1}$ at the corrugator supercilii and adductor pollicis muscles compared with the conventional induction of anesthesia with propofol.

\section{Materials and Methods}

The study protocol was approved by the Institutional Review Board of Fukuoka University, Fukuoka, Japan (Chairperson, Professor R. Nishimura) and registered at the Japan Medical Association Clinical Trials Registry (which participates in the World Health Organization (WHO) International Clinical Trial Registry Platforms (Identification no., JMA-IIA00051)). Written informed consent was obtained from each patient.

We studied 32 patients classified as having physical status I-II as judged by guidelines set by the American Society 
TABLE 1: Characteristics of patients.

\begin{tabular}{lcc}
\hline & Sevoflurane group & Propofol group \\
\hline Number $(n)$ & 16 & 16 \\
Sex (male/female) & $12 / 4$ & $8 / 8$ \\
Age (years) & $44.9 \pm 13.5$ & $42.8 \pm 12.5$ \\
Height $(\mathrm{cm})$ & $157.8 \pm 6.2$ & $160.6 \pm 7.5$ \\
Weight $(\mathrm{kg})$ & $55.4 \pm 7.7$ & $57.8 \pm 10.7$ \\
\hline
\end{tabular}

Values are mean \pm SD. No significant differences between the two groups were observed.

TABLE 2: Blood pressure and heart rate at the maximum blockade.

\begin{tabular}{lcc}
\hline & $\begin{array}{c}\text { Sevoflurane } \\
\text { group }\end{array}$ & $\begin{array}{c}\text { Propofol } \\
\text { group }\end{array}$ \\
\hline Number $(n)$ & 16 & 16 \\
Systolic blood pressure $(\mathrm{mmHg})$ & $115 \pm 21$ & $113 \pm 15$ \\
Diastolic blood pressure $(\mathrm{mmHg})$ & $75 \pm 13$ & $74 \pm 12$ \\
Mean blood pressure $(\mathrm{mmHg})$ & $88 \pm 15$ & $87 \pm 13$ \\
Heart rate (beats per min) & $66 \pm 13$ & $73 \pm 13$ \\
\hline
\end{tabular}

Values are mean \pm SD. No significant differences between the two groups were observed.

of Anesthesiologists. They were aged 18-60 years, were within $20 \%$ of their ideal body weight, and were scheduled to undergo elective minor surgery. All patients were free from hepatic, renal, or neuromuscular disease. Patients were premedicated with diazepam (10 mg, p.o.) $90 \mathrm{~min}$ before the induction of anesthesia.

Upon arrival in the operating room, pulse oximetry, electrocardiography, and noninvasive monitoring of arterial blood pressure were instituted. Patients were randomly allocated to the sevoflurane group or propofol group with the use of a random number list generated by a computer. In both groups, before induction of anesthesia, $50-100 \mu \mathrm{g}$ of fentanyl was given. In the sevoflurane group $(n=16)$, general anesthesia was induced with $5 \%$ sevoflurane in oxygen via a facemask. Patients were breathing room air before the induction of anesthesia. The anesthetic circuit was primed with sevoflurane $5 \%$ in oxygen at $6 \mathrm{~L} \mathrm{~min}^{-1}$ fresh gas flow for $30 \mathrm{~s}$. Patients were asked to take deep breaths after fitting of the facemask. The end-tidal concentration of sevoflurane was monitored continuously with an anesthetic gas monitor (AS/3, Datex-Ohmeda, Helsinki, Finland). In the propofol group $(n=16)$, general anesthesia was induced with propofol 2-2.5 $\mathrm{mg} \mathrm{kg}^{-1}$ and maintained with $10 \mathrm{mg} \mathrm{kg}^{-1} \mathrm{~h}^{-1}$ of propofol. In both groups, artificial ventilation was applied with the facemask in all patients to maintain endtidal carbon dioxide tension $\left(\mathrm{P}_{\mathrm{ETCO} 2}\right)$ between $35 \mathrm{mmHg}$ and $40 \mathrm{mmHg}$. After loss of consciousness, vecuronium $0.1 \mathrm{mg} \mathrm{kg}^{-1}$ was given over $5 \mathrm{sec}$ in both groups. Blood pressure was monitored every $2.5 \mathrm{~min}$. If systolic blood pressure fell below $80 \mathrm{mmHg}$, ephedrine $(4 \mathrm{mg}$, i.v.) was administered.

The neuromuscular monitoring was started $5 \mathrm{~min}$ before induction of anesthesia. Evoked responses to train-of-four (TOF) stimuli were measured by acceleromyography (TOFGuard; Organon Instruments, Boxtel, The Netherlands) at the corrugator supercilii and adductor pollicis muscles. The temporal branch of the facial nerve was stimulated supramaximally every $15 \mathrm{~s}$ at the external part of the superciliary arch, and an acceleration transducer was fixed to the left medial eyebrow [10]. Another pair of electrodes was applied to stimulate the ulnar nerve supramaximally every $15 \mathrm{~s}$ at the left wrist. The acceleration transducer was fixed to the volar side of the distal phalanx of the left thumb. Signals from the corrugator supercilii muscle were amplified five times because of the low responses of this muscle. Onset time was defined as the time from the end of vecuronium injection until $95 \% \mathrm{~T} 1$ depression. The trachea was intubated, and, after intubation, anesthesia was maintained with sevoflurane $1.5-2.5 \%$ in oxygen and air or $6-10 \mathrm{mg} \mathrm{kg}^{-1} \mathrm{~h}^{-1}$ propofol with controlled ventilation. Fentanyl was given intermittently at the discretion of each anesthesiologist in charge. Times to $25 \%$ recovery of $\mathrm{T} 1$ at both muscles between the groups were also compared. Incremental doses of vecuronium were administered at the discretion of anesthesia staff. Neuromuscular monitoring was continued until the end of anesthesia.

\section{Statistical Analyses}

For the analysis of patient characteristics, a Chi-squared test and analysis of variance (ANOVA) were used. Differences in onset time as well as times to $25 \%$ recovery of $\mathrm{T} 1$ between sevoflurane and propofol groups induced by vecuronium at each muscle were compared using ANOVA. Differences in onset time, times to $25 \%$ recovery of $\mathrm{T} 1$, and recovery of train-of-four ratio between the adductor pollicis and the corrugator supercilii muscles in each group were compared using repeated-measures ANOVA (Stat View 5.0 software for Windows; SAS Institute, Cary, NC, USA). All tests were two sided; $P<0.05$ was considered significant.

From our pilot study, we found that the standard deviation of onset time with vecuronium $\left(0.1 \mathrm{mg} \mathrm{kg}^{-1}\right)$ at the corrugator supercilii muscles was $28 \mathrm{~s}$. This indicated that a sample size of 14 patients per group was needed to detect a $30 \mathrm{~s}$ difference in onset time at a 5\% significance level with a power of $80 \%$.

\section{Results}

There were no statistically significant differences between the groups with regard to sex ratio, age, height, and weight (Table 1). End-tidal concentrations of sevoflurane at the time of loss of consciousness and at the time of maximum blockade in the sevoflurane group were $3.1 \pm 0.4 \%$ and $3.9 \pm 0.3 \%$, respectively. Differences in mean arterial blood pressure and heart rate at the nearest measuring point from maximal blockade were similar between the sevoflurane group and propofol group (Table 2).

The neuromuscular effects of vecuronium are summarized in Table 3. The onset time after administration of vecuronium $\left(0.1 \mathrm{mg} \mathrm{kg}^{-1}\right)$ was significantly shorter in the sevoflurane group than in the propofol group at the corrugator supercilii and adductor pollicis muscles $(P<0.01)$. 
TABLE 3: Neuromuscular effects of vecuronium.

\begin{tabular}{lcc}
\hline & $\begin{array}{c}\text { Sevoflurane } \\
\text { group }\end{array}$ & $\begin{array}{c}\text { Propofol } \\
\text { group }\end{array}$ \\
\hline Onset(s) & $127 \pm 29^{*}$ & $155 \pm 27$ \\
Adductor pollicis & $(112-143)$ & $(140-169)$ \\
Corrugator supercilii & $107 \pm 28^{* \#}$ & $138 \pm 34^{\#}$ \\
$(92-122)$ & $(120-156)$ \\
\hline T1 recovery to 25\% of control (min) & $51.5 \pm 10.9^{*}$ & $37.6 \pm 6.4$ \\
Adductor pollicis & $(44.9-58.0)$ & $(33.8-41.5)$ \\
Corrugator supercilii & $38.5 \pm 4.2^{\dagger \#}$ & $33.8 \pm 6.4^{\#}$ \\
Train-of-four ratio at the end of & $(36.0-41.1)$ & $(30.0-37.7)$ \\
anesthesia & & \\
Adductor pollicis & $0.97 \pm 0.06$ & $0.97 \pm 0.05$ \\
& $(0.93-1.01)$ & $(0.93-1.00)$ \\
Corrugator supercilii & $1.12 \pm 0.12^{\#}$ & $1.01 \pm 0.17$ \\
& $(1.05-1.20)$ & $(0.91-1.13)$ \\
\hline
\end{tabular}

Values are mean \pm SD; $95 \%$ confidence interval is given in parentheses. ${ }^{*} P<0.01,{ }^{\dagger} P<0.05$ compared with the propofol group. ${ }^{\#} P<0.01$, compared with the adductor pollicis muscle.

The onset time was significantly shorter at the corrugator supercilii muscles than at the adductor pollicis muscles for both groups $(P<0.01)$. The times to $25 \%$ recovery of $\mathrm{T} 1$ were significantly longer in the sevoflurane group than in the propofol group at both muscles $(P<0.05, P<0.01)$. The times to $25 \%$ recovery of $\mathrm{T} 1$ were significantly shorter at the corrugator supercilii muscles than at the adductor pollicis muscles for both groups $(P<0.01)$.

\section{Discussion}

Compared with the propofol group, the sevoflurane group had a shorter onset time and a delayed recovery of neuromuscular blockade induced by vecuronium at the corrugator supercilii and adductor pollicis muscles. We measured neuromuscular blockade at these two muscles because (i) the time course of neuromuscular blockade at the corrugator supercilii muscles is similar to that at laryngeal muscles and (ii) the adductor pollicis is a useful and convenient site for anesthesiologists to monitor the effects of neuromuscularblocking drugs [10]. A shorter onset time at the corrugator supercilii muscle indicates a shorter onset time at the laryngeal muscles during sevoflurane induction than during propofol induction.

The effects of sevoflurane on the onset of neuromuscularblocking drugs have been studied only at adductor pollicis muscles. Yamaguchi et al. evaluated the effects of inhalation of sevoflurane as an induction agent on the onset time of neuromuscular-blocking drugs [9]. They reported that induction with $8 \%$ sevoflurane accelerated the onset time of $0.1 \mathrm{mg} \mathrm{kg}^{-1}$ vecuronium compared with induction with propofol [9]. Conversely, using intravenous agents for the induction of general anesthesia, several authors reported that the onset time of nondepolarizing neuromuscular-blocking drugs was not shortened by sevoflurane at concentrations $<2 \%$. Suzuki et al. administered vecuronium during general anesthesia with $1.7 \%$ sevoflurane after induction with intravenous agents. They demonstrated that sevoflurane did not shorten the onset time of vecuronium $0.1 \mathrm{mg} \mathrm{kg}^{-1}$ compared with balanced anesthesia using propofol or midazolam [6]. Lowry et al. reported that, for those aged 18-65 years, after induction with propofol, the onset times of rocuronium $0.6 \mathrm{mg} \mathrm{kg}^{-1}$ during maintenance with a 1.5 minimum alveolar concentration (MAC) of sevoflurane or with propofol were similar [7]. They also reported that, after the induction of general anesthesia with propofol, 1.5 MAC of sevoflurane did not shorten the onset of mivacurium [11]. High concentrations of sevoflurane used for the induction of general anesthesia in the present study and those in the study of Yamaguchi et al. may be the reason for accelerated onset time despite the relatively short duration of exposure time to sevoflurane. Concentrationdependent inhibition of neuromuscular transmission by sevoflurane has been reported in animal and human studies $[12,13]$.

Pharmacokinetic factors may also have been involved in the accelerated onset by sevoflurane in the present study. Induction with a high concentration of sevoflurane compared with propofol has been shown to have a strong dilatory effect on peripheral vessels during the induction of general anesthesia [14]. Ogawa et al. evaluated the effects of autonomic circulatory control during induction with $5 \%$ sevoflurane and propofol and showed that, although the reduction in autonomic nervous modulation of the heart was similar, the reduction in sympathetic modulation of peripheral vessels was greater in the sevoflurane group [14]. Circulation time, cardiac output, and regional blood flow affect the onset time of neuromuscularblocking drugs [15-17]. We did not measure hemodynamic parameters such as cardiac output and systemic vascular resistance. The precise pharmacokinetic mechanisms that affect the onset of vecuronium need further investigation.

In the present study, the times to $25 \%$ recovery of T1 were significantly longer in the sevoflurane group than in the propofol group at the corrugator supercilii and adductor pollicis muscles. This is in accordance with a study using a similar concentration of sevoflurane for maintenance of general anesthesia examined at the adductor pollicis muscles. Suzuki et al. demonstrated that, after an intubating dose of vecuronium $\left(0.1 \mathrm{mg} \mathrm{kg}^{-1}\right)$, the duration of incremental doses of vecuronium $\left(0.02 \mathrm{mg} \mathrm{kg}^{-1}\right)$ was prolonged by $1.7 \%$ sevoflurane compared with anesthesia induced by propofol or midazolam [6].

In conclusion, induction with sevoflurane resulted in accelerated onset and delayed recovery of neuromuscular blockade induced by vecuronium at the corrugator supercilii and adductor pollicis muscles.

\section{Conflict of Interests}

The authors declared that there is no conflict of interests. 


\section{Acknowledgments}

This work was supported by grants from the Clinical Research Foundation, Fukuoka, Japan. This clinical trial has been registered at JMA Clinical Trials Registry which participates in the WHO International Clinical Trial Registry Platforms, https://dbcentre3.jmacct.med.or.jp/jmactr/ Default_Eng.aspx. Identification number: JMA-IIA00051.

\section{References}

[1] S. Ghatge, J. Lee, and I. Smith, "Sevoflurane: an ideal agent for adult day-case anesthesia?" Acta Anaesthesiologica Scandinavica, vol. 47, no. 8, pp. 917-931, 2003.

[2] R. Liao, J. Li, and J. Liu, "Volatile induction/maintenance of anaesthesia with sevoflurane increases jugular venous oxygen saturation and lumbar cerebrospinal fluid pressure in patients undergoing craniotomy," European Journal of Anaesthesiology, vol. 27, no. 4, pp. 369-376, 2010.

[3] S. Yogendran, A. Prabhu, A. Hendy et al., "Vital capacity and patient controlled sevoflurane inhalation result in similar induction characteristics," Canadian Journal of Anesthesia, vol. 52, no. 1, pp. 45-49, 2005.

[4] T. Suzuki, H. Nagai, N. Katsumata, S. Ogawa, and H. Suzuki, "Comparative neuromuscular inhibitory effects of volatile anesthetics," Japanese Journal of Anesthesiology, vol. 45, no. 5, pp. 599-607, 1996.

[5] M. Naguib, M. Seraj, and E. Abdulrazik, "Pipecuroniuminduced neuromuscular blockade during nitrous oxidefentanyl, enflurane, isoflurane, and halothane anesthesia in surgical patients," Anesthesia and Analgesia, vol. 75, no. 2, pp. 193-197, 1992.

[6] T. Suzuki, K. Munakata, N. Watanabe, N. Katsumata, S. Saeki, and S. Ogawa, "Augmentation of vecuronium-induced neuromuscular block during sevoflurane anaesthesia: comparison with balanced anaesthesia using propofol or midazolam," British Journal of Anaesthesia, vol. 83, no. 3, pp. 485-487, 1999.

[7] D. W. Lowry, R. K. Mirakhur, G. J. McCarthy, M. T. Carroll, and K. C. McCourt, "Neuromuscular effects of rocuronium during sevoflurane, isoflurane, and intravenous anesthesia," Anesthesia and Analgesia, vol. 87, no. 4, pp. 936-940, 1998.

[8] B. Woloszczuk-Gebicka, T. Lapczynski, and W. Wierzejski, "The influence of halothane, isoflurane and sevoflurane on rocuronium infusion in children," Acta Anaesthesiologica Scandinavica, vol. 45, no. 1, pp. 73-77, 2001.

[9] S. Yamaguchi, H. Egawa, K. Okuda, M. Mishio, Y. Okuda, and T. Kitajima, "High concentration sevoflurane induction of anesthesia accelerates onset of vecuronium neuromuscular blockade," Canadian Journal of Anesthesia, vol. 48, no. 1, pp. 34-37, 2001.

[10] B. Plaud, B. Debaene, and F. Donati, "The corrugator supercilii, not the orbicularis oculi, reflects rocuronium neuromuscular blockade at the laryngeal adductor muscles," Anesthesiology, vol. 95, no. 1, pp. 96-101, 2001.

[11] D. W. Lowry, R. K. Mirakhur, M. T. Carroll, G. J. McCarthy, D. A. Hughes, and R. A. O'Hare, "Potency and time course of mivacurium block during sevoflurane, isoflurane and intravenous anesthesia," Canadian Journal of Anaesthesia, vol. 46, no. 1, pp. 29-33, 1999.

[12] P. Matthias, R. M. Fokt, C. H. Kindler, N. C. J. Dipp, and C. S. Yost, "Characterization of the interactions between volatile anesthetics and neuromuscular blockers at the muscle nicotinic acetylcholine receptor," Anesthesia and Analgesia, vol. 95, no. 2, pp. 362-367, 2002.

[13] K. Nitahara, Y. Sugi, K. Higa, S. Shono, and T. Hamada, "Neuromuscular effects of sevoflurane in myasthenia gravis patients," British Journal of Anaesthesia, vol. 98, no. 3, pp. 337341, 2007.

[14] Y. Ogawa, K. Iwasaki, S. Shibata, J. Kato, S. Ogawa, and Y. Oi, "Different effects on circulatory control during volatile induction and maintenance of anesthesia and total intravenous anesthesia: autonomic nervous activity and arterial cardiac baroreflex function evaluated by blood pressure and heart rate variability analysis," Journal of Clinical Anesthesia, vol. 18, no. 2, pp. 87-95, 2006.

[15] H. Iwasaki, M. Igarashi, S. Kawana, and A. Namiki, "Accelerated onset of vecuronium neuromuscular block with pulmonary arterial administration," Canadian Journal of Anaesthesia, vol. 41, no. 12, pp. 1178-1180, 1994.

[16] J. A. Kuipers, F. Boer, E. Olofsen, J. G. Bovill, and A. G. L. Burm, "Recirculatory pharmacokinetics and pharmacodynamics of rocuronium in patients: the influence of cardiac output," Anesthesiology, vol. 94, no. 1, pp. 47-55, 2001.

[17] M. Chauvin, C. Lebrault, and P. Duvaldestin, "The neuromuscular blocking effect of vecuronium on the human diaphragm," Anesthesia and Analgesia, vol. 66, no. 2, pp. 117122, 1987. 


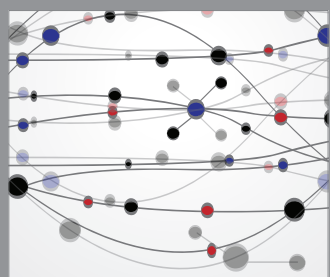

The Scientific World Journal
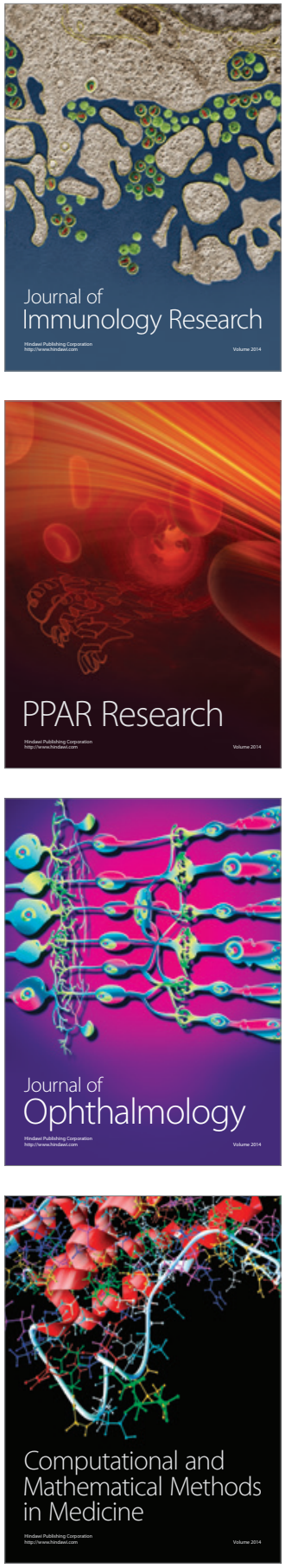

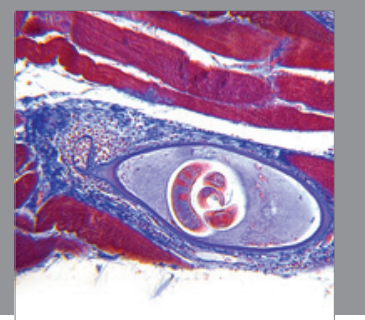

Gastroenterology

Research and Practice
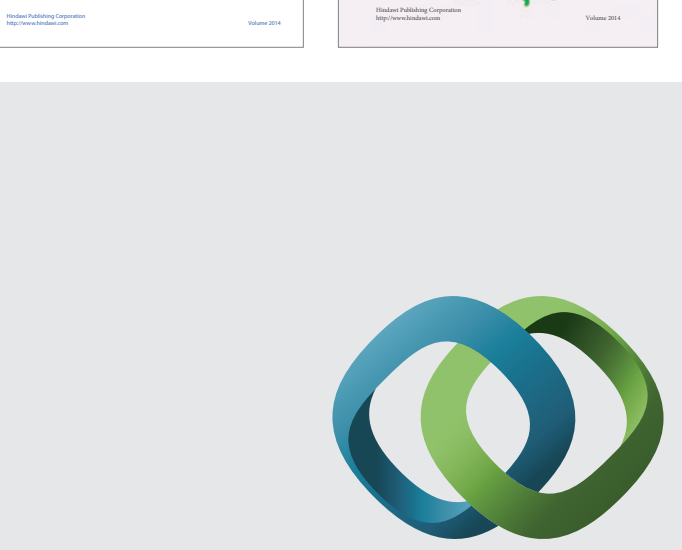

\section{Hindawi}

Submit your manuscripts at

http://www.hindawi.com
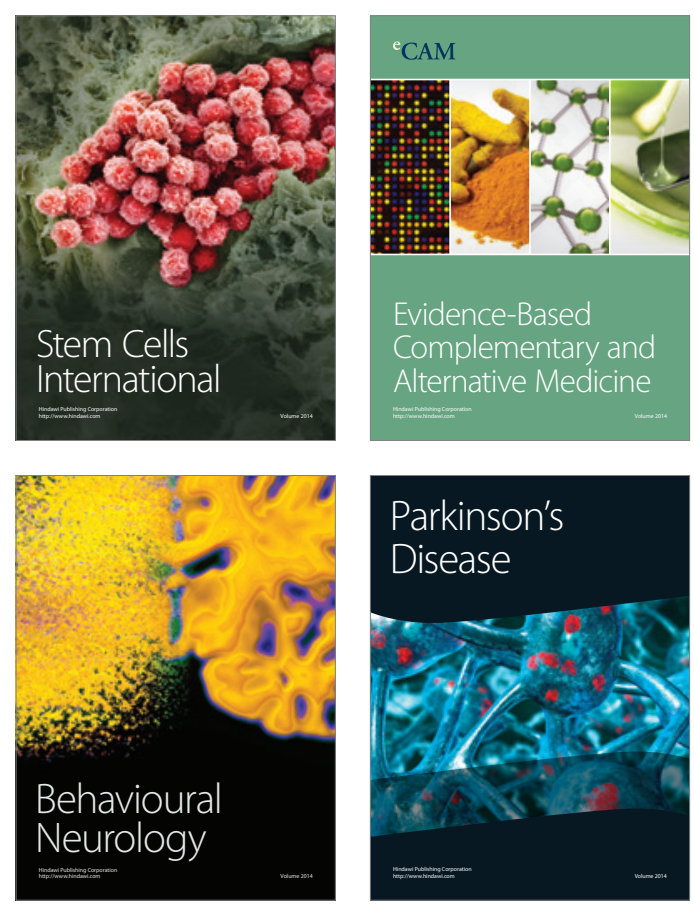

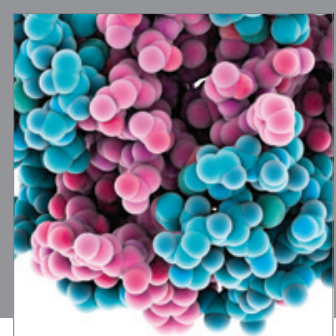

Journal of
Diabetes Research

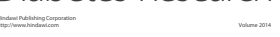

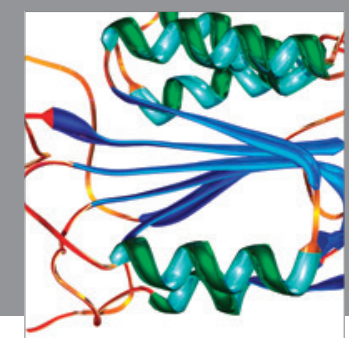

Disease Markers
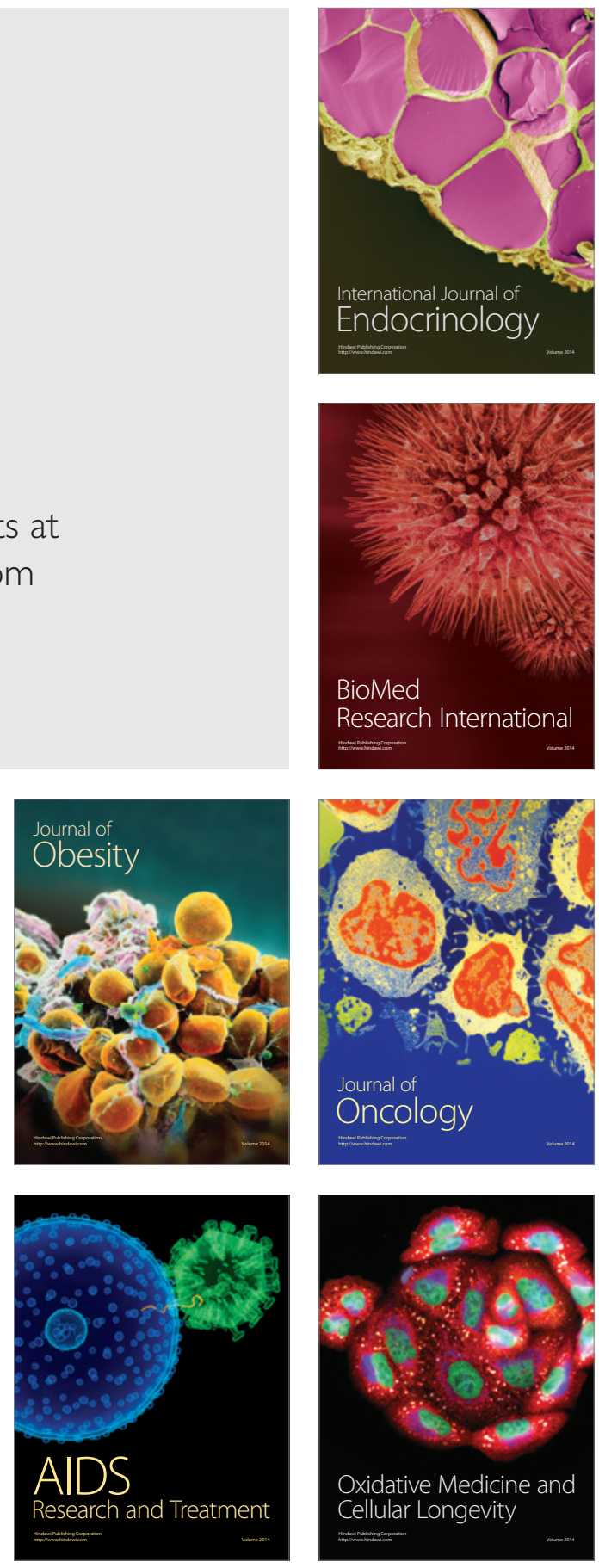